\title{
Sport, development and the political-economic context of Zambia
}

This chapter examines how the wider political and economic context in Zambia has been influential in shaping the historical governance of sport and the expansion of the SfD 'movement' in the country. As the previous chapter has shown, within the academic literature most attention has been paid to the global expansion of SfD; a further, smaller body of work has considered the emergence and development of particular $\mathrm{SfD}$ organizations and programmes. What are largely absent are attempts to connect these various levels of analysis and explore how the emergence of SfD in particular localities has been influenced by wider political and economic trends affecting both sport and 'development. The analysis in this chapter therefore addresses a current lacuna in understandings of SfD. Within the book, it assists our overall aim of localizing global SfD, by offering a detailed account of how SfD in Zambia reflects the influence of multilayered political and economic contexts. This provides the foundation for our later chapters, in which we examine both how SfD is delivered by NGOs in Zambia, and how young people respond to it.

In exploring these connections, the chapter shows how the development of sport sectors in Zambia, particularly in the area of $\mathrm{SfD}$, reflects wider trends in the country's political governance and development approaches. Some aspects of these trends are specific to Zambia, but others are shared with other African countries. Broadly speaking, the governance of development across various international contexts has progressed through three phases (Batley and Rose, 2011), and in this chapter we explore these through a historical timeline which considers firstly, Zambia's immediate post-independence period in which expanded social and welfare services were state-provided; secondly, the subsequent imposition of neo-liberal reforms and policies; and thirdly, more recent developments in the relationships between the Zambian state and civil society. As with all such analyses, the temporal boundaries between phases are blurred, and this is especially the case when we examine the relationship between trends 
in SfD and in other policy sectors. This is addressed throughout the chapter and returned to in more detail in the concluding section.

Given the topics covered in this chapter, our own positioning as co-authors merits brief reflection. The chapter is most influenced by Davies' personal history of being born and living in postcolonial Zambia, and his subsequent doctoral studies examining this period; these bring an indigenous understanding to the political and economic context and developments described in this chapter. Iain, Tess and Ruth first visited in 2006 and hope to have become more informed since, but our perspectives clearly remain those of outsiders. The chapter therefore draws on this mixture of personal perspectives and knowledge, informed by increasing engagement with the literature on development policy and governance, to offer an analysis of the emergence and governance of SfD in Zambia.

The chapter uses empirical data from a variety of sources. It draws throughout on interviews undertaken originally for Davies' PhD from 2008 to 2010. These especially inform the consideration of sport policy and provision after Zambian independence, and include interviews with officials from the MSYCD and NSCZ as well as with colonial-era sports administrators and journalists. The sections concerning the subsequent emergence and evolution of the SfD sector also make use of interviews with representatives of NGOs, governmental agencies and Northern donor organizations undertaken in 2007. The chapter has additionally been informed by documentary analysis of national development plans (NDPs) and national sports policy documents, and by the grey literature on Zambian SfD (Kruse, 2006; Chipande, 2010) and academic accounts of Zambia's development and associated policies (Noyoo, 2008). All of these sources of information have been supplemented by ongoing informal conversations with stakeholders in the Zambian SfD sector.

\section{State governance and sport in post-independence Zambia}

No examination of sport in post-independence Zambia is complete without recognizing the influence of the preceding period of colonial rule. From 1911 to 1963 , Northern Rhodesia, as it was then known, had been administered alongside other southern African countries, firstly by the British South African Company and then the British Colonial Office. Colonial rule entrenched deep inequalities both across the wider region and within the country itself. Resource distribution and development of infrastructure such as schools and social amenities explicitly favoured British interests in Southern Rhodesia (now Zimbabwe) 
and South Africa to the expense of those in Zambia. Within the country, racial segregation and exploitation severely affected the life chances and opportunities of the indigenous Africans who made up the majority of the population. The contours of colonial rule also applied to sports, which were divided into 'expatriate sports' and 'African sports', with white settlers and natives having separate sports governing federations. In white-settler residential areas, white expatriates played golf, rugby, cricket and bowls. Amongst the African population, sports such as football and boxing gained significant popularity despite vastly inferior facilities. Provision of and access to sport and recreation were thus distributed unequally according to race and class, and also clearly gendered.

In the late 1950s, Zambia's nationalist movement emerged alongside those in other sub-Saharan countries, fuelled not only by the injustices of colonial rule within the country but also its exploitation relative to its neighbours (Noyoo, 2008). After the end to British rule was announced on 29 March 1963, the first multiparty democratic elections held in January 1964 were won by an overwhelming margin by Kenneth Kaunda's UNIP. Influenced by fellow leaders of African independence and nationalist movements, Kwame Nkrumah of Ghana and Julius Nyerere of Tanzania, Kaunda introduced the philosophy of 'humanism' to the people of Zambia (Simutanyi, 2006). Zambia thus became part of a group of newly independent African states that followed a broadly socialist agenda, contrasting with the alternative capitalist policies adopted in countries such as Kenya and Senegal (Nugent, 2004). In terms of social policy, Kaunda’s humanist socialism sought to rectify some of the imbalances in human development and provision that were present under colonial rule (Simutanyi, 2006). As in other newly independent African countries (Batley, 2006), there was significant expansion of government social provision, with services such as education and health provided free of charge to the Zambian public. There was also largescale investment in other aspects of Zambia's physical and social infrastructure (Noyoo, 2008). Less progressively, there was little government impetus to address gender inequality that was, as in similar African nations, entrenched across the country's economy and society.

Aspects of national policy orientated towards sport show both similarities and differences with Kaunda's broader agendas. Although sport was not a particular policy priority, in Zambia as in many other former colonies it became part of the desire to redress some of the consequences of colonialism. Zambia's first two NDPs, covering the period from 1966 to 1974 (GRZ, 1966, 1971) included proposals to construct new sports facilities in rural areas (GRZ, 1971) - part of the broader aspiration to bridge urban-rural divides by improving rural 
infrastructure and diversifying Zambia's economy. Although many of these rural facilities were never built, a 30,000-capacity National Independence Stadium was constructed in Lusaka to host celebrations of the transition from colonial rule. The stadium also represented the government's prioritization of elite sport and signalled its intention that its construction would enable Zambia to host the All Africa Games. From the earliest days of independence, sport was therefore seen as a symbol of Zambia's developing national identity, aspirations which were shared with many other African countries emerging from colonialism (Nugent, 2004).

This support for elite urban-centred sport was in contrast to the socialist agendas of Kaunda's government. Further evidence of sport policy contradicting the supposed focus on humanism can be found elsewhere in the second NDP, in which priority was to 'be given to football which [was] to act as a source of funds and stimulant for other kinds of sport' (GRZ, 1971:23). Activities promoting the involvement of men in football were also the prime recipient of financial support from the Cultural and Sporting Fund that was instituted in 1964 (Liwena, 2005). Such divergences between rhetoric and reality were by no means isolated in the early period following Zambia's independence.

A key feature of early post-independence governance was a process of 'Zambianization', in which natives were installed in positions that previously only their colonizers had been allowed to occupy. Such changes took place within the administrative offices of central and local government, the judiciary, the legislature, and within particular policy sectors, such as education and health. In sport, immediately prior to and post independence, this led to the reconstitution of those sport associations that were previously white only. For example, in football, the Northern Rhodesia National Football League was formed shortly before independence, incorporating white and native teams and leagues, and was then renamed the Zambia Football Association (later Football Association of Zambia) on independence. However, in some sporting associations white settlers were resistant to relinquishing their leadership positions (Liwena, 2005). Moreover, the process of Zambianization was constrained by the widespread shortage of qualified native personnel, which affected sport as it did the public and private sectors more generally. The issue continued beyond the early years of independence, compounded by the importance the government attached to Zambia's successes in international sport. By the time of the third NDP, covering the period 1979-83 (GRZ, 1979), the government was negotiating on behalf of national governing bodies of sport for experts from abroad to train Zambians as sports coaches and administrators. This import of external expertise reflected 
the government's desire to maintain and extend elite sporting success after Zambia emerged runner-up to Zaire in the final of the 1974 African Cup of Nations.

Beyond Zambianization, the trajectory of governance in Zambia transformed relatively quickly in a way that was typical of many other newly independent African countries. Phiri (2006: 152) identifies that the hangover of colonial rule meant that 'Zambia as a nation lacked the strong political society capable of maintaining liberal democracy'. Furthermore, in common with Ghana's Nkrumah and Tanzania's Nyerere, Kenneth Kaunda did not believe in multiparty democracy from the outset (Nugent, 2004; Phiri, 2006). Thus, his presidency became increasingly authoritarian not so much in response to the resistance of opposition parties, but owing to internal conflicts and politics within the UNIP. The de facto start of one-party rule came in 1969, when opposition parties were no longer recognized in Zambia's parliament. For Phiri (2006: 153), the one-party state was 'in essence a return to the much-criticized bureaucratic authoritarianism of the pre-independence days'. For another scholar of Zambian political and social history, this was 'one of the darkest times in Zambia's history. In this era, dissent and alternative views from those of the ruling party were thwarted ... the one-party state effectively snuffed out the plurality of the Zambian society' (Noyoo, 2008: 49). As in other African countries in which authoritarian regimes emerged, the early years of the oneparty state provided little space for civil society, or any of its organizations, to flourish.

Similar centralization of power was evident in the governance of sport. There were attempts in the early years after independence to create a Department of Youth Development and Sport in government, and both a National Sports Advisory Council (subsequently the NSCZ) and National Olympic Committee of Zambia were established. However, upon the instigation of the one-party state, the UNIP Central Committee became the party's, and thus the government's, supreme policy-making body. Under the Central Committee, the Youth and Sport Sub-Committee comprised political appointees who wielded their power to influence all sport policy-related matters. Government officials were answerable to the Sub-Committee, which had the mandate to appoint or dismiss board members of statutory bodies such as the National Sports Advisory Council (Banda, 2010). There was frequent interference by UNIP party members in the running of NSAs, particularly in relation to the selection of the Football Association chairman. With the Sub-Committee also having substantial influence on the distribution of resources to sporting 
organizations, policymaking for sport was highly centralized and implemented in a top-down fashion.

Centralization and, in particular, nationalization were also strongly evident in the governance of Zambia's economy. Kaunda viewed the private sector's former dominance of Zambia's economy as the reason for the country's 'underdevelopment and backwardness' (Muuka et al., cited in Banda, 2010), and public control of the economy was therefore portrayed in successive NDPs as the solution to Zambia's development problems. Nationalization of key industries, especially of the mining sector, was seen as a means of funding priorities in infrastructure and social provision as well as addressing inequalities between rural and urban areas (Simutanyi, 2006). Across the African continent, nationalization was also seen as a protection against the imperialism that came with foreign ownership and investment (Rolfe and Woodward, 2004). Four years after gaining independence, the Zambian government implemented the Mulungushi Reforms of 1968, taking a 51\% stake in foreign-owned mining companies and converting them to SOCs (Potter 1971; Turok 1979).

Nationalization of key industries had significant implications for the implementation of sport policy. Alongside the Zambian uniformed security wings (army, air force and police), the newly formed SOCs became key providers of opportunities across all levels of sport, from participation to elite. SOCs, as well as the uniformed security wings, formed and sponsored sport and recreation departments that funded the development and maintenance of facilities, ran annual sports festivals and entered teams in competition across various sporting codes. For example, in elite sport, approximately $65 \%$ of the football teams in the Zambian premier league were owned by different mining operations. The standard of coaching in mining communities was considered to be high, partly as a result of white expatriate mineworkers who volunteered to coach local teams. Nevertheless, there remained significant inequalities in sporting opportunities and participation. Based on the geographical positioning of mining areas and most SOCs, sporting opportunities were skewed in favour of the Copperbelt region and locations along the line of Zambia's single railway, which runs from there, through Lusaka and onwards to Livingstone. Similarly, there remained strongly gendered dimensions to sport provision, reinforced as a result of the occupational orientation of SOCs' provision. Female participation was dependent on the employment status of male family members, with those native Zambians whose relations were in relatively well paid senior posts being more likely to become involved in expatriate sports, such as golf or bowling (Banda, 2010). 


\section{Neo-liberal governance, rolling back the (Zambian) state and the emergence of SfD NGOs}

As in other African countries (Nugent, 2004), Zambia's economy initially prospered after independence. In the first ten years of independence, the average annual growth in Zambia's economy was 2.4\% (McCulloch et al., 2000). For Noyoo (2008: 48), this period was one in which 'the government had indeed scored very high marks as it elevated the living standards of Zambians and, without a doubt, it was a very caring one'. However, Zambia's initially strong economic performance was not to be sustained (Nugent, 2004), with a combination of internal and external factors contributing to subsequent economic crises and ongoing decline. The imposition of the one-party state had suffocated enterprise and innovation, and engendered high levels of corruption (Noyoo, 2008). In particular, the monopoly positions of SOCs meant that they were mismanaged and highly inefficient. Moreover, in common with many African countries that had a colonial legacy of being economically dependent on single commodities (Binns et al., 2012), the Zambian government failed in its stated aim to diversify the economy from its base in copper production. As a result, the country had little economic protection when the international price of copper collapsed from 1974 (Nugent, 2004). Zambia was amongst many African countries that were also hit by the increased cost of importing petroleum following the world oil crises of 1974 and 1979.

With the Zambian government dependent on income from the SOCs, all public services were significantly affected by the economic decline. For example, in the education sector, Noyoo states:

It was not accidental that when the economy faltered and began to tumble the education sector followed suit. From primary, all the way to university level, the education sector felt the reverberations of the economic collapse. There were also no mechanisms to make sure the gains made in education could benefit future generations. (Noyoo, 2008: 123)

A similar decline occurred in the sport sector, despite ongoing NDPs and other policy documents indicating a desire for continued development of sport. With the SOCs being central to the provision of sport, there were particular repercussions of the cutting of government subsidies to these companies. Provision of annual elite sport events declined as SOCs such as the Zambia Consolidated Copper Mines, which funded football tournaments, and Zambia Airways, which sponsored netball, withdrew their sponsorship. Plans for new facility development were not implemented and, instead, existing facilities began to fall into 
disrepair. Moreover, the devaluation of the local currency made it extremely expensive to procure sports equipment. The comparatively low governmental priority for sport and recreation meant that the sector was also affected by spillover effects from other constrained policy areas. Attempts to limit government spending led to reductions in teacher recruitment and training. As head teachers sought to strengthen their schools' core curriculum offer by recruiting teachers qualified in prioritized academic subjects, physical education (PE) was marginalized as a subject and the status of trained PE teachers further diminished. Overall, such factors led to considerable weakening in PE and sport provision in schools as well as in grass-roots, community-based opportunities for young people more generally.

It would be stating the obvious to say that the rapid decline in Zambia's economy had significant long-standing implications. Zambia's external debt, which stood at US\$814 million in 1970, increased exponentially over the following two decades to reach US\$6916 million by 1990 (Situmbeko and Zulu, 2004). That the majority of this borrowing was from the International Monetary Fund (IMF) and the World Bank placed Zambia in a 'recipient' relationship with these donor organizations. Like other similarly indebted countries, Zambia had little choice but to implement the neo-liberal economic reforms that comprised the Structural Adjustment Programmes (SAPs) instigated by the IMF and World Bank from 1983. Nevertheless, Zambia's economic performance continued to weaken, with its GDP declining continuously from the early 1980s, except for a brief period from 1987 when, under pressure from trade unions, Kaunda abandoned SAP reforms and reimposed state control of interest rates, imports and foreign exchanges.

Kaunda was not able, however, to continue resistance in the face of international pressures, nor was he able to retain his hold on power. While political liberalization of the one-party state was promoted by international donors, Phiri (2006) and Bwalya et al. (2011) argue that the transition to multiparty democracy was largely a result of a critical mass of pressure from Zambian grass-roots civil society organizations that formed as a result of, and were motivated by, collapsing living standards. UNIP and Kaunda no longer had the economic means to buy compliance from key constituencies within the population (Nugent, 2004). Multiparty parliamentary and presidential elections were finally held in October 1991 and were won by the emergent Movement for Multiparty Democracy (MMD) led by Frederick Titus Chiluba. After 27 years in power, Kaunda oversaw the first peaceful and elected transition of power between political parties in a previously British colony. 
Nevertheless, Chiluba's presidency saw little change in overarching, internationally dominated, neo-liberal economic policies, with the implementation of SAPs actually becoming intensified upon the change of government (Situmbeko and Zulu, 2004). A rapidly accelerated process of privatization of major SOCs was implemented and, concurrently, there was a broader shrinking of the Zambian state and the decimation of nationally provided public services. Similar trends were witnessed across Africa, as the international impetus for implementation of neo-liberal ideologies was only strengthened by the perception that national governments were both failing and corrupt (Zaidi, 1999; Laird, 2007). In Zambia, despite the end of the one-party state, corruption and patronage became even more entrenched during Chiluba's presidency (Noyoo, 2008). Nevertheless, the re-emergence of multiparty democracy enabled greater pluralism in political processes and the provision of social services. Previously, any nonstate provision of education and health services had solely been the preserve of missionary and faith-based organizations, working largely in rural locations. Expansion of, often loosely categorized, civil society organizations that became involved in development-orientated sectors came not only as a result of Zambia’s return to plural politics but also through internationally instigated policies associated with the rhetoric of 'decentralization' and crises resulting from the contraction of state provision. This trend was common across Africa and resulted in an 'unprecedented increase' during the 1980s and 1990s in the number of NGOs operating in countries across the continent, including Zambia (Bebbington and Riddell, 1997; Laird, 2007). International donors increasingly funded NGOs, based on the perception that they were more effective in enabling aid to reach the poorest members of society (Bebbington and Riddell, 1997; Zaidi, 1999) and represented, more generally, 'vehicles for "democratization" [as part of] a thriving civil society' (Hulme and Edwards, 1997: 6).

The implications of these general trends can be seen in a number of sectors relevant to our studies. In Zambia's education sector from 1991, the government encouraged increasing diversification in the types of schools in different localities (Noyoo, 2008). Remaining government schools struggled to meet demand and, in more affluent areas, private schools began to charge significant fees that were beyond the means of the majority of the population. In other areas, there was a dramatic increase in the number of community schools which, as their name suggests, were founded and managed by members of local communities. While some of these schools benefitted from financial support from a variety of international donors, many were also dependent on the work of volunteer, or poorly recompensed, teachers and staff. Similarly, in the health sector, both in 
Zambia and in other countries, much of the burden to fill emergent gaps in state provision fell upon both international and locally emerging NGOs (Boone and Batsell, 2001). This trend was only strengthened by the emergence of HIV/AIDS and the initial lack of political will, both globally and nationally, to address the disease (Garbus, 2003; Piot et al., 2007). In a common trend across African countries and beyond, the Zambian government was itself slow to respond to the emergence of HIV/AIDS, despite formally recognizing it as a national emergency in 1986. As a result, a proliferation of NGOs emerged both in Zambia and more broadly across countries in the global South to address the pandemic (Mercer et al., 1991; Hershey, 2013).

The trends identified in international development, and in Zambia's health and education sectors, were slower to emerge in its sport sector. Despite its relatively low priority, throughout the 1990s there remained a very much statecentred approach to sport policy and implementation, with the principal providers of sport services limited to state and state-recognized organizations, such as the national associations for particular sports. Early overseas support for Zambian sport actually bucked the broader trends in other sectors, with the NIF commencing funding for the NSCZ in 1991, supporting 'Sport for All' programmes as it also did in Tanzania and Zimbabwe at the time (Kruse, 2006; Straume, 2012). Nevertheless, the limitations of state sport provision highlighted earlier continued to deepen, with the resultant gaps creating an opportunity for other organizations to emerge and establish community sports activities. Initial pilot programmes were delivered by the subsequent founders of SfD NGOs from 1996 (Mwaanga and Mwansa, 2014), with EduSport and Sport in Action later founded formally as the first local and indigenous SfD NGOs in Zambia in 1999.

These new SfD NGOs quickly moved to gain legitimization from local communities and, perhaps most importantly, international support for their activities. Achieving local legitimization was aided by EduSport and Sport in Action positioning themselves as addressing education and health issues that had become increasingly important as public services weakened. Internationally, a broader realignment of the Norwegian government's international development policy towards supporting NGOs coincided with the recognition of problems with the NIF's previous support for the NSCZ. As a result, NIF funding was reallocated to the benefit of both of Zambia's fledgling SfD NGOs. At the same time, the broader international development priorities of Norway and its primary funding agency, NORAD, were quickly adopted within Zambian SfD. Besides HIV/AIDS and poverty reduction, women's rights and gender equality 
(NORAD, 2000; Norwegian Ministry of Foreign Affairs, 2007) became important priorities for EduSport and Sport in Action. The leaders of these NGOs had innovatively identified a suitable niche for attracting donor funding towards sport and physical activities. Whether this represented the 'entrepreneurial spirit' referred to by Kidd (2008) or the 'opportunism' in response to available international funding identified by some development studies authors (e.g. Fisher, 1993; Meyer, 1995) is probably a matter of individual perspective.

The emergence of EduSport and Sport in Action led to SfD gaining increasing recognition both in Zambia and beyond. Leaders from these NGOs, working alongside NORAD and the NIF as well as other African organizations such as Kenyas MYSA, helped to found the international KAO Network of organizations, pioneering SfD work orientated around HIV/AIDS (KAO, n.d.). The setting up of the KAO Network helped to increase the international profile of $\mathrm{SfD}$ as well as securing further funding for the Zambian NGOs themselves. Within a year of its foundation in 2001, UK Sport and Commonwealth Games Canada had also joined the KAO Network and begun to fund programmes in Zambia. Separately, further international SfD NGOs also began work in Zambia, with Right to Play establishing a National Office in 2002 and Grassroot Soccer doing likewise in 2005. Alongside this, a multitude of indigenous organizations both within and outside the sport sector engaged in $\mathrm{SfD}$, with researchers from one South African university reporting that over 200 organizations, including schools, youth groups and community organizations, were using sport for development purposes in Lusaka alone (Jeanes and Kay, 2010).

Two points are particularly relevant here with regard to this influx and expansion of SfD organizations in Zambia. First, interviewees with international experience have recognized a greater prevalence of $\mathrm{SfD}$ organizations in Zambia compared with other countries in southern Africa. This can be attributed to the categorization of Zambia as a low-income country, but one that has been relatively politically stable and peaceful, with low levels of social unrest. Countries of similar status at the start of the twenty-first century, such as Uganda, Malawi and Mozambique, also began to receive increased international aid as donors restructured geographical target zones for aid away from countries such as South Africa (Canadian International Development Agency (CIDA), 2000, 2002; NORAD, 2000; DfID, 2000). The expansion of SfD has again followed this wider trend, with one representative of a Northern SfD organization suggesting that in Zambia it is probably the donor driven environment which has created so many NGOs overnight because the money has been there, the aid money has been there, the opportunities are there' 
Second, and as shall be explored in more depth in the next chapter, the approaches of both local and international SfD NGOs in Zambia demonstrated a minimal level of integration with national or local governmental policies. Within the sport sector, in particular, early relations between SfD NGOs and governmental agencies, such as the NSCZ, lacked integration and were instead largely antagonistic. Resentment among government agencies was fuelled by the diversion of Norwegian and subsequent donors' resources from the NSCZ towards the newly emergent SfD NGOs, which further depleted the funds available to NSCZ to support its established implementation structures. In addition to their growing international profile, the initiators of the SfD NGOs also gained local media publicity for their organizations, which they believed further angered representatives of the NSCZ. Claims of political bias were raised in regard to the SfD NGOs, and attempts were made to have their status as NGOs, conferred by the Zambian Register of Societies, revoked. These initial difficulties in relationships between state agencies and SfD NGOs and across the sport and SfD sectors were only to continue, as we shall consider in the following section.

\section{Mixed modes of governance and the evolution of the SfD movement in Zambia}

With policies of neo-liberal reform in Zambia and other African countries being enforced by a strong consensus amongst key international donors and multinational agencies, criticisms were not slow to emerge and these gradually began to prompt change in approaches to international development governance. From the early to mid-1990s, international policymakers and donors came to join governments in the global South in increasingly voicing their frustration at the lack of evident progress in addressing long-standing development priorities (Hill, 2002; Samoff, 2004; Chansa et al., 2008). In fact, in Zambia, many development indicators continued to stagnate at best, or more often decline, with per capita GDP figures (Figure 1) falling continuously from the 1970s to reach a nadir in the 1990s. With similar trends occurring in Zambia's overall HDI and component measures of health, education and living standards (Figure 2), Zambia slipped from the $73^{\text {rd }}$ percentile of the global HDI countries in 1980 to the $89^{\text {th }}$ percentile by 2000 .

In terms of development governance, a variety of interlinked factors, evident to different extents in Zambia and its SfD sector, were globally understood as contributing to this lack of progress. International funding for the delivery of stand-alone programmes by NGOs was strongly criticized for being 


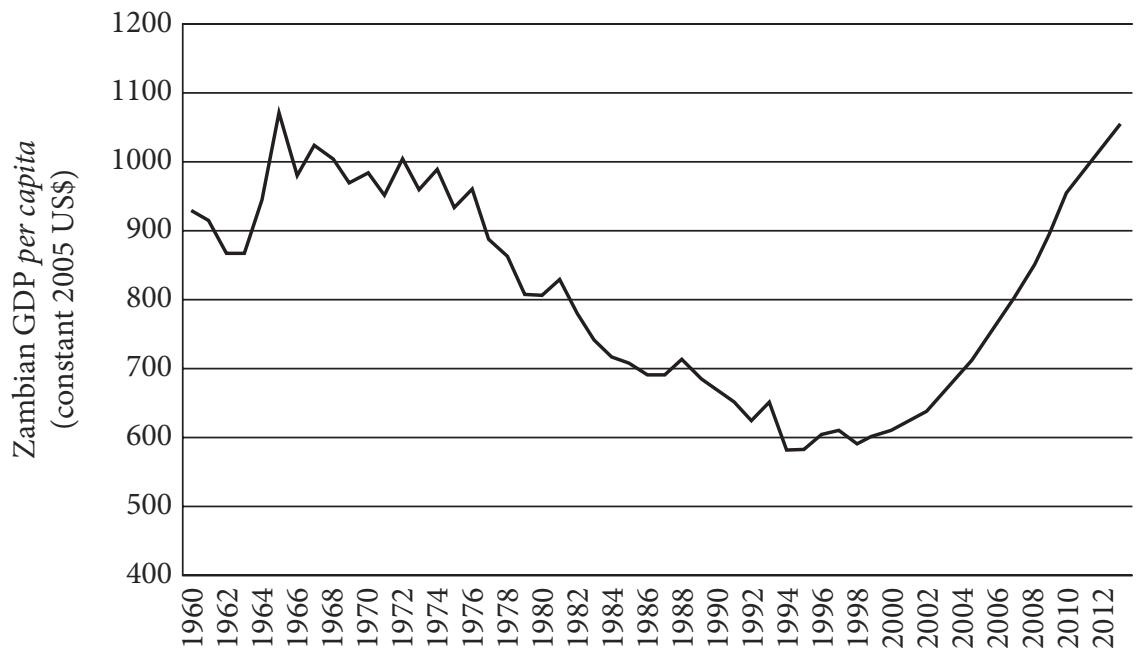

Figure 1 GDP per capita in Zambia over time (constant 2005 US\$)

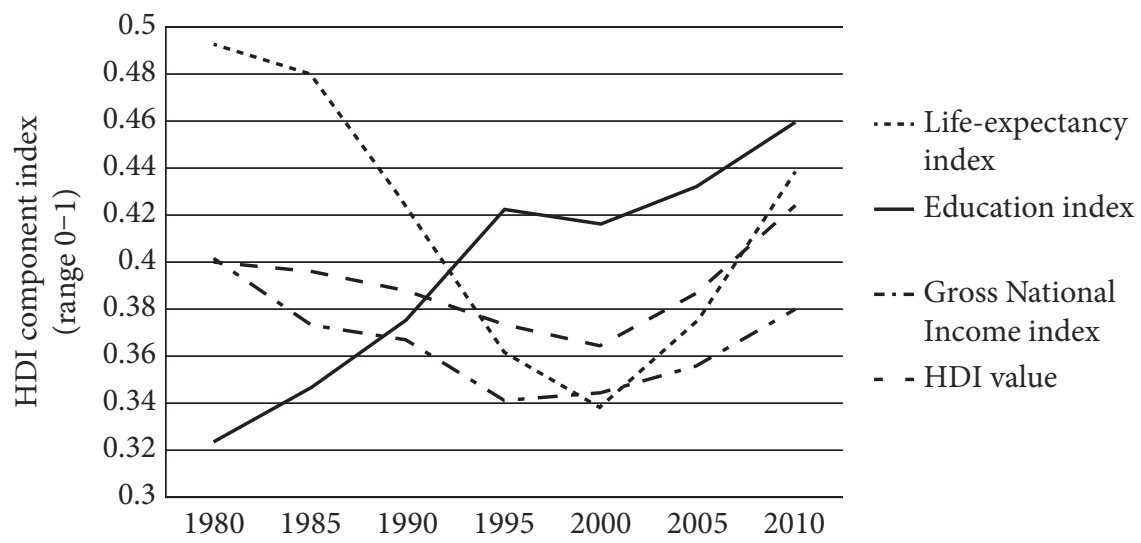

Figure 2 Trends in Zambia’s HDI component indices 1980-2010

unsustainable and inhibiting local ownership (Zaidi, 1999; Samoff, 2004; Chansa et al., 2008; Leiderer, 2012). Similar views were expressed by indigenous interviewees from the Zambian SfD sector, with Right to Play being cited as a particularly notable example. Not only was Right to Play viewed by indigenous stakeholders as implementing internationally driven programmes, but their sustainability was at best questionable, given the organization's subsequent withdrawal from the country in 2009. Play Soccer was another international NGO to instigate activities in Zambia, only to withdraw from the country 
at a later date. Even when there was greater longevity in the involvement of international donors, funding remained orientated to specific and sometimes time-limited programmes. For example, UK Sport concurrently contributed to the management of funding allocated to EduSport's Go Sisters (which was awarded $£ 500,000$ in 2008) and to the II programme, which ran in Zambia from 2007 to 2010 supported by funding allocated to promote the legacy of the London 2012 Olympic Games. Norwegian funding stands in something of a contrast to these common trends in international development. With ongoing support from NORAD, the NIF has actually increased its funding for a range of SfD organizations and programmes to an annual total of approximately US\$1 million (NIF, 2013). This Norwegian support has also been unusual in contributing to organizational sustainability by supporting core administrative costs, as well as specific programmes.

Further critiques of development governance that have resonance in the Zambian SfD sector are those that relate to the limited scope and fragmentation of organizations and their activities. Reviewing the operation of NGOs in the health sectors in various African countries, Lorgan (1998: 329) observed that they 'often work in limited geographical areas and do not have the scale or resources to assure national coverage or uniformity'. Competition between NGOs has also been widely recognized in other development sectors (Hulme and Edwards, 1997; Moore and Stewart, 1998; Webb, 2004) as well as being briefly mentioned in the SfD literature (Kidd, 2008; Wilson and Hayhurst, 2009). With much of the work of SfD NGOs being (at least initially) restricted to the more urbanized 'line of rail' through Zambia, interviewees highlighted overlaps and duplication in provision in these areas. For example, one representative of a Northern donor organization working in Zambia referred to SfD NGOs 'working in the same communities, with very similar objectives and very similar programmes', while a staff member of a Zambian SfD NGO spoke about competition with other organizations:

You feel sometimes you are competing for the same resources, we are competing for the same target, we are competing for the same consequences, so you find that most of the time there is some kind of competition among the groups that are involved.

A further interviewee from a Zambian SfD NGO attributed this competition to dependence on international funding, indicating, 'We were left with only one source [of funding] and when we are left with one source you automatically become competitors.' Rather than advocate or necessarily pursue reform, the 
response to the problem of competition from the same Northern donor representative was that: 'I think a lot of funders and even the government are turned away by the fact that there is such a competitive nature now and so many different NGOs.'

Such a response stands in contrast to the aspirations underpinning the subsequent global impetus towards reform of development systems and sectors. Major international donors' acceptance of the weaknesses of neo-liberal policies and reforms led to a series of 'seminal' policy documents concerning development governance and 'aid effectiveness' published by the World Bank in 1993 (Hill, 2002), the Organisation for Economic Co-operation and Development in 1996 and 2005 (in its 'Paris Declaration'; Altenburg, 2007; Gore, 2013), and the UN between 2002 and 2007 (Batley et al., 2012). These documents signified an emerging consensus on the need for development governance to be reoriented, in part towards the instigation and expansion of sector-wide approaches (SWAps) in internationally assisted countries in the global South. As suggested by their name, SWAps were initiated to provide a more integrated approach to development efforts in particular sectors. In the Zambian health sector, for example, aspirations for a SWAp emerged as far back as 1992 (Sundewall and Sahlin-Andersson, 2006).

It is perhaps indicative of a dislocation between global SfD and international development more broadly that only a single, brief reference to SWAps can be found in international SfD policy documents (SDPIWG, 2008a: 259). Nevertheless, elements that are considered key to SWAps in other development sectors provide a valuable frame for analysis of ongoing governance issues in the Zambian SfD sector. Prominent amongst these key elements was an aspiration for SWAps to reverse the power traditionally held by international donors and instead be country-led through leadership by national governments (Samoff, 2004; Sundewall and Sahlin-Andersson, 2006). The centrality of governments was also seen as important to counter the previous prioritization of NGOs, reflecting recognition in the development studies literature that 'only the government has the capacity to mount a nationwide response effort, and to harness the expertise of NGOs as part of that effort' (Batsell, 2005: 70). The government of Zambia also itself sought an increasing role across development sectors with the late President of the Republic Levy Mwanawasa (2004) stridently and somewhat provocatively pointing to the relative advantages of greater government responsibility for development: 'Government can be called to account for funding. These NGOs just chew the money and carry on [with] business as usual: no-one asks them anything.' 
Certainly in terms of HIV/AIDS, as shall be seen in the next chapter, the advent of the Zambian NAC in 2002 put this and other state organizations at the centre of the multisectoral approach to addressing the disease. However, it has also been claimed that the emergence of stand-alone policies and funding mechanisms specifically to address Zambia's HIV/AIDS crisis hindered a 'full SWAp' being achieved in the country's broader health sector (Sunderwall and Sahlin-Andersson, 2006; Chansa et al., 2008). Similarly, a number of studies and reviews have shown that implementation of SWAps, and progress towards increased governmental involvement in particular, has been problematic. For example, Moran's (2006) review found significant variation in government leadership across different development sectors and countries. More specifically, Palmer's (2006: 238) empirical study of health sectors across five African and Asian countries demonstrated 'piecemeal' approaches on behalf of governments in their relationships with NGOs. Such diversity of governmental leadership, involvement and relationships can be considered inevitable given the geographical and sectoral breadth of development efforts.

Within international SfD policy documents and academic literature, there have been numerous calls for greater involvement on the part of in-country governments (e.g. SDPIWG, 2008a, b; Kidd, 2008; Levermore and Beacom, 2009b; Commonwealth Secretariat, 2014). Certainly, in Zambia there has been increasing recognition of SfD within national government and sport policy. Of rhetorical significance, at least, the late President Levy Mwanawasa opened the Next Step sport and development conference in Livingstone in 2005 with a speech that acknowledged the role that sport could play in addressing critical issues affecting Zambian society, including HIV/AIDS (Mwanawasa, 2005). It was in this speech that Mwanawasa also announced that PE was to become a mandatory subject across all education levels, a declaration that Njelesani (2011) credits as heralding the revitalization of the subject. Subsequent policies have continued to indicate growing state interest in SfD. The fifth NDP (2006-11) included stronger and more explicit statements in support of the use of sport for development purposes than previous iterations. For example, a significant steer was given to organizations, particularly state-funded actors, to 'institutionalize the use of sport, physical education and recreation activities as viable tools for mitigating the impact of HIV and AIDS and substance and rights abuse among children and youth' (GRZ, 2006: 222). Such statements in the NDP provided a new context for sport in Zambia which was explicitly recognized in 2009 in the production, for the first time since 1994, of a new National Sports Policy (MSYCD, 2009). 
However, despite these developments, Zambia's SfD sector continues to lack a specific operational policy framework, a second key element of SWAps. Interviewees from indigenous SfD NGOs acknowledged being involved in consultative forums, instigated by the MSYCD, that considered the formulation of the 2009 National Sports Policy. Nevertheless, despite the resultant policy being rationalized in terms of a wide range of potential developmental outcomes of sport, it specified little in the way of actions towards these outcomes (MSYCD, 2009). Pertinently, of the three departments within the MSYCD, the Department of Sport Development was the only one that lacked operational plans to mainstream efforts to address HIV/AIDS. As a result, the NSCZ and its affiliated institutions, the NSAs, also lagged behind in mainstreaming HIV/AIDS in comparison with other sectors funded by government.

Furthermore, the adoption of other potential roles by the Zambian government and its agencies in the SfD sector has been limited. Governmental regulation of development sectors has been an area where improvements have been limited across different countries (Batley and Mcloughlin, 2010) and has been largely nonexistent in Zambian SfD, after the initial conflicts regarding registration of SfD NGOs. It was acknowledged by interviewees that there had been greater informal recognition within government, and the MSYCD in particular, of the role of SfD NGOs. However, governmental officials also complained of a lack of information regarding the ongoing activities of SfD NGOs, a minimal requirement of any system of regulation. In the National Sports Policy (MSYCD, 2009), any substantial mention of NGOs is notable by its absence, especially in comparison to the in-depth consideration of other stakeholders, especially NSAs.

Beyond regulation, Palmer (2006) and Batley and Mcloughlin (2010) also identify co-production and contracting of service provision as further potential roles of government. That such joint implementation activities have been limited in Zambian $\mathrm{SfD}$ is unsurprising given the relative budgets of government and NGOs. For example, in 2006, a total of approximately US $\$ 130,000$ was allocated by the MSYCD for sport for all, youth sport and SfD, which collectively represented about $6 \%$ of the total government budget allocated to sport. The main focus of the budget and of state agencies remained largely orientated to supporting football and elite sport. In line with the importance of core budgetary support within SWAps (Samoff, 2004; Booth, 2011), the NIF continued to provide support for the NSCZ, but has been the only international donor to do so, and only to the tune of approximately US $\$ 16,000$ per year from 2006 . This sum was dwarfed by the US $\$ 400,000$ provided by the NIF to the KAO Network, 
Sport in Action and EduSport in the same year (Kruse, 2006). Significant investment into the non-governmental sport sector in Zambia also came in respect of Olympic Solidarity funding for the establishment of an Olympic Youth Development Centre in Lusaka that cost US\$10.3 million and opened in 2010. These disparities in international funding have only served to exacerbate tensions between government agencies and NGOs. Where international donors have mandated the involvement of government agencies alongside NGOs in particular programmes, such as II, such arrangements have also proved to be problematic in their implementation.

A third key element of SWAps, linked to the first two of greater government involvement and the development of an integrated policy approach for the sector, is to enhance sector-wide co-ordination amongst donors and between in-country stakeholders (Samoff, 2004; Gore, 2013). The need for such co-ordination in the Zambian SfD sector was recognized by interviewees representing both in-country and international stakeholders. Initial progress towards harmonization of funding and support (Altenburg, 2007) provided by the NIF, UK Sport and Commonwealth Games Canada was aided by the advent of the KAO Network in 2001. Funding from these donors was only to be provided to members of the KAO Network, and a representative of a Northern donor organization that was a member of the network spoke of this being, at that time, a novel approach:

We combine our funding, the three of us, rather than individually funding different partners, we combined our funding and worked with the same partners. That was the original concept of why it was better to work together to make sure we weren't competing and we weren't creating that [competitive] environment.

Common systems of monitoring and evaluation were also identified between these three international donors. However, this co-ordinated approach subsequently dissipated as UK Sport, for example, was required to follow different accountability mechanisms as it increasingly accessed funding from other development agencies such as the UK's DfID.

In-country, the establishment of a Zambia-specific KAO Alliance, that closely followed the creation of the original international KAO Network, was a further development that could have supported greater co-ordination (Chipande, 2010). However, Kruse reports a lack of clarity in respect of the purpose of the KAO Alliance and 'a tendency to keep out new small grassroots organizations' (2006: 20), with its membership mainly comprising the larger SfD NGOs in Zambia. 
By 2006, the KAO Alliance was dissolved as competition for funding led to, as one interviewee put it, 'relationship disintegration' between its members.

Since then, the achievement of greater co-ordination across the Zambian SfD sector has remained a relatively unfulfilled aspiration, although informal observations and conversations have pointed to improved personal relationships between key Zambian SfD stakeholders. This has resulted in SfD NGOs working together on specific, often internationally funded, programmes and events. For example, Sport in Action and EduSport have worked together over ten years in facilitating volunteering in Zambia by UK students as part of UK Sport's IDEALS programme. German support, aligned with the South African World Cup in 2010, established a Zambian chapter of their Sport for Social Change Networks, although the membership was remarkably similar to that of the previous Zambian KAO Alliance. Again, the impetus for this formal network, as well as any co-ordination that may have come with it, appeared to dissipate once international funding and support ceased. Co-ordination amongst SfD NGOs has therefore remained largely informal and piecemeal, with positive developments in some locations, including Livingstone, countered by the continued competitive pressures affecting different organizations, especially in Lusaka.

An area in which there has been some newly developed collaboration has been in respect of efforts to mainstream HIV/AIDS activities within Zambia's NSAs. Lacking specific, specialized or ring-fenced resources of their own, a number of NSAs have collaborated with SfD NGOs in order to mainstream HIV/AIDS activities. In such joint working, it has usually been the NGOs that have contributed most significantly to both the planning and delivery of activities. In contrast, the availability of funding from FIFA through its ' 11 for Health' programme enabled the Football Association of Zambia to work with teachers to deliver its own HIV/AIDS activities in schools. This example reinforces the difficulty of developing greater co-ordination across Zambia's SfD sector when international funding and the power of some local organizations can enable more stand-alone approaches.

\section{Conclusions}

In this chapter we have drawn on multiple sources to offer a decentred account of the emergence and development of SfD in Zambia. Our intention has been to complement and extend the more internationally focused approaches to analysing SfD that have been predominant in the academic literature to date. 
Situating SfD in the context of Zambia's wider social, economic and political trajectory has highlighted how the complex interaction of global, international and local influences has resulted in Zambian SfD sometimes mirroring wider trends but at other times running counter to them. This suggests that analysis of global influences needs to be complemented by attention to local specifics to provide a nuanced understanding of how SfD is configured within a single nation and in particular local contexts.

This decentred analysis therefore both departs from and reinforces literature which explains the development of SfD primarily in terms of the influence of global policies and international donors (Hartmann and Kwauk, 2011; Darnell, 2012). In examining the specific emergence of EduSport and Sport in Action, for example, this chapter highlighted the importance of multiple locally specific factors, including the role of indigenous Zambian individuals in establishing the NGOs in 1999, in advance of key developments in global SfD; the strong orientation of both organizations towards addressing social problems in local communities; and the extra stimulus provided by the paucity of existing sporting provision. Alongside this, however, our analysis also suggests that problems in local communities were themselves a consequence of broader economic problems in Zambia, that the shrinking of state-sponsored provision was a manifestation of the international imposition of neo-liberal economic policies and that the decision of the NIF to shift the focus of its funding to NGOs arose from the wider trend within development to do so. Our analysis is not, therefore, intended to suggest that local factors negate or override global influences, but rather to highlight that it is the complex interactions between influential factors at different levels that shape SfD in specific contexts.

Our understanding of the role of SfD NGOs in Zambia has benefitted from applying insights from the wider critical development studies literature to SfD. At the time that SfD NGOs were emerging within Zambia, problems associated with scope, fragmentation, long-term sustainability and local ownership of NGOs were already being witnessed in the country's more established development sectors. Although some of these issues have been addressed in relation to SfD NGOs (e.g. Giulianotti, 2011b; Huish, 2011; Kidd, 2011), including brief consideration of state-NGO relationships (Kidd, 2008), they have been subject to more significant appraisal in the development studies literature. Applied to $\mathrm{SfD}$ in Zambia, these analyses draw particular attention to the limited relationships between the SfD NGOs and state structures, and show how SfD continued to hold marginal status both in relation to the wider sport sector and within Zambian development policies and structures more generally. 
Further, comparison with other development sectors and literature also draws attention to particularities associated with the timescales for change within the Zambian SfD sector. A number of developments in Zambian sport and $\mathrm{SfD}$, such as the shift from state-based provision to the emergence of an expanded and strengthened civil society sector, have lagged behind similar trends in other sectors. Further, while movement towards a health SWAp in Zambia was somewhat in advance of the global impetus to develop alternatives to neo-liberal governance, in contrast, similar forms of governance have yet to significantly emerge within the Zambian SfD sector at the time of writing. These findings emphasize the importance of detailed and temporal comparison between processes and developments within SfD and those external to it.

The analysis in this chapter also confirms the difficulty of applying clear distinctions to the structures and activities of SfD. The blurring of 'sport development' and 'sport for development' had been evident from the outset in Zambian SfD; the first SfD NGOs not only sought to address the social problems faced by their communities, but also the lack of sport provision in them, and the programmes they established contributed to both these objectives. More recently, the traditional sport development roles of NSAs have also become less clearly delimited as some have begun to address HIV/AIDS. The issue of gender inequality is a further example that cuts across historical sports development and more recent SfD efforts; gender equity has been addressed both within Zambian sport, to overcome under-provision for females, and through it, in programmes using sport as a vehicle for gender empowerment. This suggests that as well as contextualizing SfD within national and international politicaleconomic conditions as discussed above, it is also important to analyse it in the context of broader sport systems.

In conclusion, the chapter overall has highlighted how the complex trajectory of SfD in Zambia has created a fluid, diverse and fragmented sector. It is possible that in time SfD will follow trends in other development sectors to develop greater coherence and unity; many of our international and in-country interviewees suggested, however, that the institutionalized problems that SWAps were intended to address in the wider development sector remain evident in SfD. Despite, or in some cases because of, the numerous personal connections between individuals with significant roles in Zambian SfD, efforts to develop more co-ordinated approaches across the sector have largely failed to overcome more influential forces engendering competition between different agencies. Zambian state agencies have lacked both the capacity and the will to contribute to efforts to introduce more co-ordinated approaches. The same could be said 
for international donors, who have themselves been constrained by their own dependence on accessing external funding. Our analysis therefore again points to the complexity of interrelated influences on Zambian SfD that operate at different levels and on different scales. It also points to the significant constraints on addressing recognized but intractable and institutionalized problems affecting SfD in Zambia. Indications within the SfD literature, as well as some of our research elsewhere (Lindsey, 2014a), would suggest similar problems may be occurring in SfD within other country contexts. However, further comparative research, informed by understandings from development studies literature and including locally focused empirical enquiry, is required both to explore this suggestion more fully and to identify any differential progress to addressing such problems. Such work will complement existing SfD scholarship and help to rebalance the current prevalence of research which gives empirical primacy to international perspectives. 